\title{
CUTTING PERFORMANCE OF DEEP CRYOGENIC TREATED AND NITRIDED HSS CUTTING TOOL INSERTS
}

\author{
Sanja ŠOLIĆ, Zdravko SCHAUPERL, Vlado TROPŠA
}

\begin{abstract}
High speed steel (HSS) is a very important industrial tool material and has been constantly improved for different wear resistance applications and cutting tools, i.e. drills, milling cutters, hobs and for the cutting tools in which the economical cutting speed is too low for choosing the carbide tools. The properties of HSS depend significantly on the parameters of the conducted heat treatment. In this paper, the influence of deep cryogenic treatment in combination with nitriding of metallurgical powder metallurgy HSS on the wear resistance was measured. Additionally, the cutting performance in a single point cutting tool machinability test at the configuration of the dry low-speed turning of steel was investigated. The results showed that deep cryogenic treatment itself, and in combination with nitriding, resulted in the reduction of the wear rate. The results of the single point cutting tool machinability test showed that deep cryogenic treated and nitrided HSS inserts performed worse than the classically heat-treated inserts and deep cryogenic treated HSS inserts exhibited approximately the same flank wear as the nitrided ones.
\end{abstract}

Keywords: deep cryogenic treatment; cutting tools; high speed steel; nitriding; wear resistance

\section{INTRODUCTION}

High speed steel (HSS) is a very important industrial tool material and has been constantly improved for different wear resistance applications and cutting tools, i.e. drills, milling cutters, hobs and for the cutting tools in which economical cutting speed is too low for choosing the carbide tools. When cutting, the tool moves through the material of the workpiece by removing the chip from its surface. The tribological conditions that appear in the contact between these two surfaces in mutual motion are very demanding. The contact temperature of steel machining can range from $900{ }^{\circ} \mathrm{C}$ to $1300{ }^{\circ} \mathrm{C}$ [1-3]. According to Holmberg et al. [1], 80\% of the heat produced in the machining process is caused by the mechanical deformation of the chip, $18 \%$ by friction between the chip and the upper surface of the tool and only $2 \%$ is created on the tool tip. Of the heat eliminated, about $75 \%$ is eliminated by the chip, $5 \%$ is absorbed by the workpiece and $20 \%$ is conducted through the tool, but note that these values change depending on the processing conditions, mostly speed and feed. Generally, there are four main mechanisms of tool wear that are present in metal cutting tools, namely abrasive wear, adhesive wear, delamination wear and wear due to chemical instability, including diffusion, solution and electrochemical wear $[2,3]$.

Abrasive wear takes place on tool surface and is caused by hard particles, usually carbides, oxides and some silicates in the work material, and it is responsible for the tool flank face wear. Abrasive wear appears in the same amount regardless of the cutting speed and cutting temperature. The adhesive wear of cutting tools is the result of the formation of micro-welded joints between the chip and the tool face and the breaking of joints by the shearing force which tears out particles of tool material and adheres it to the chip or the workpiece. Adhesive wear occurs in low cutting speeds at the flank face of the tool when contact temperatures are not very high. Delamination wear occurs when HSS tools soften due to annealing during machining. It is the result of the plastic deformation of the surface which leads to subsurface crack nucleation, propagation and fallout of wear particles from the tool surface. Wear due to chemical instability occurs with high cutting speeds and high cutting temperatures [2].

The properties of high-speed steels depend significantly on the parameters of conducted heat treatment [4].

Authors in [5] reported that using different heat treatment parameters with different additional heat treatment and thermo-chemical processes increases tool steel properties and its wear resistance and can be adjusted for specific application. The application of deep cryogenic treatment (DCT) in the heat treatment of high speed steel tools has resulted in increased wear resistance and dimensional stability of the treated material $[6,7]$. Combining DCT with various austenitization temperatures results in a different volume of retained austenite which affects the hardness and fracture toughness [8,9] of certain tools, but it can also affect the enhancement in wear resistance regardless of the hardness $[10,11]$.

In the recent years, numerous authors have studied the influence of deep cryogenic treatment on a variety of HSS and tool steel properties. Authors in [8] compared the wear behaviour of a vacuum heat treated and the deep cryogenic treated at $-196^{\circ} \mathrm{C}$ ESR AISI M2 HSS in combination with four different tempering temperatures. The presented results showed that in general, DCT samples had better wear resistance compared to the vacuum heat treated samples with improvement in their fracture toughens and hardness. Authors in their review [12] concludes that the improvement gained by DCT is mainly due to the complete elimination of the retained austenite and the formation of nanometre sized carbides dispersed in the tempered martensitic structure. Authors [13] investigated the influence of different heat treatment parameters (austenitizing temperature, cooling rate, holding time, heating rate, and tempering temperature) which all directly influence the effect of DCT on tool steel 
properties. The results showed that the most significant parameters in terms of mechanical properties are austenitizing and tempering temperatures. A low austenitizing temperature combined with a high tempering temperature improves fracture toughness, bending strength and elongation, while the high austenitizing and low tempering temperatures improve hardness and wear behaviour.

Authors in [14] analysed the influence of DCT with different austenitizing and tempering temperatures on fracture toughness, hardness and wear resistance of PM lower C, high W and Co cold work tool steel, high C and V PM cold work tool steel and PM HSS. They reported that in the case of low carbon cold-work tool steel, the DCT results greatly improved in fracture toughness, while maintaining high hardness, which can be linked to the formation of finer needles such as martensite and martensitic transformation accompanied by plastic deformation of the primary martensite. On the other hand, for high $\mathrm{C}$ cold-work tool steel, the DCT has a negative effect, while for high-speed steel, the DCT has virtually no impact on its properties. They also reported an alteration in fracture toughness/Rockwell hardness ratio which affects wear resistance of cold-work tool steel. It was concluded, however, that hardness is still a major parameter affecting abrasive wear resistance.

The application of DCT to HSS cutting tools has been enhanced in the recent years due to its effect in the prolonging of tool life, dimension stability and stress relief. Authors in [15] reported that the M2 HSS twist drills tool life increased for approximately $280 \%$ when drilling steel, taking the total failure of tools as a criterion for determining the tool service life. Authors in [16] reported a $77 \%$ and $126 \%$ improvement tool life of DCT and tempered M2 tool steel drills.

Authors in [17] investigated the combined impact of the cryogenic temperature with tempering on the mechanical properties and wear resistance of the W9 HSS. They concluded that all varieties of DCT influenced the wear resistance and hardness of W9 HSS. The performance of the W9 HSS taps during the tapping test was not notably influenced by the DCT temperature. It was shown that tool life was the longest when treated in the temperature range of -196 to $-160{ }^{\circ} \mathrm{C}$ with subsequent tempering, and it was concluded that for treatment effectiveness and cost efficiency, the deep cryogenic treatment at $-160{ }^{\circ} \mathrm{C}$ could be the optimal choice.

Authors [5] investigated the impact of different time and temperature DCT parameters and the combination of DCT and plasma nitriding on the wear performance of powdermetallurgy HSS considering the wear resistance and resistance to galling under dry sliding conditions. They concluded that DCT improves the microstructure of PM HSS generating the finer needle-like martensitic structure, which results in higher hardness and better wear resistance properties, especially considering friction, and galling resistance against stainless steel which considerably improves with longer cryogenic treatment times. They also concluded that plasma nitriding improves tribological properties of PM HSS and reduces the effect of austenitizing temperature, but the results indicated that if combined with
DCT, it could eliminate the advantageous influence of deepcryogenic treatment.

It is clear that an optimized combination of cryogenic treatment temperature and time, cooling rate, and subsequent tempering would make the best of sub-zero treatment while balancing the cost and performance of the material.

The purpose of this paper is to study the influence of deep cryogenic treatment, in combination with nitriding, of powder metallurgy high speed steel on the wear resistance and cutting performance in a single point cutting tool machinability test at the configuration of the dry low-speed turning of steel.

\section{MATERIALS AND METHODS}

The material used in this study was a high speed steel produced by powder metallurgy, grade PM S390 MC. The chemical composition of steel is presented in Tab. 1.

Table 1 Chemical composition of the PM S390 MC high speed steel \begin{tabular}{|c|c|c|c|c|c|c|c|c|}
\hline$\% \mathrm{C}$ & $\% \mathrm{Si}$ & $\% \mathrm{Mn}$ & $\% \mathrm{Cr}$ & $\% \mathrm{Mo}$ & $\% \mathrm{~V}$ & $\% \mathrm{~W}$ & $\% \mathrm{Co}$ & $\% \mathrm{Fe}$ \\
\hline
\end{tabular} \begin{tabular}{|l|c|c|c|c|c|c|c|c|}
\hline 1.64 & 0.60 & 0.30 & 4.80 & 2.00 & 4.80 & 10.40 & 8.00 & rest \\
\hline
\end{tabular}

For wear resistance-testing, disc shaped samples were prepared with the dimensions of $\varnothing 22 \times 4 \mathrm{~mm}$. For the purpose of a single point cutting tool machinability test or turning test, 20 cutting tool inserts were prepared according to the ISO 13399, CNMA 120408, Fig. 1, with the dimensions shown in Tab. 2.

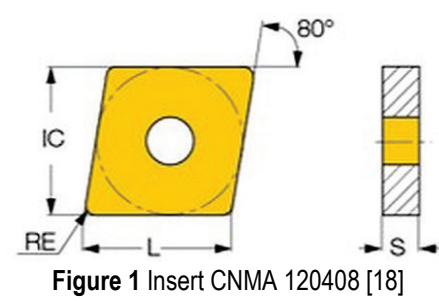

Table 2 CNMA 120408 insert dimensions

\begin{tabular}{|c|c|c|c|c|}
\hline Grade & $L, \mathrm{~mm}$ & $I C, \mathrm{~mm}$ & $S, \mathrm{~mm}$ & $R E, \mathrm{~mm}$ \\
\hline CNMA 120408 & 12.9 & 12.7 & 4.76 & 0.8 \\
\hline
\end{tabular}

The heat treatment was performed in an Ipsen vacuum furnace with the preheating parameters $650^{\circ} \mathrm{C} / 30 \mathrm{~min}, 850$ ${ }^{\circ} \mathrm{C} / 20 \mathrm{~min}, 1050{ }^{\circ} \mathrm{C} / 15 \mathrm{~min}$ before the heating to the austenitization temperature. The heating rate to the austenitization temperature of $1130^{\circ} \mathrm{C}$ was $5^{\circ} \mathrm{C} / \mathrm{min}$ and the austenitization lasted $6 \mathrm{~min}$, after what samples were quenched in the nitrogen flow, $p=1050$ mbar. The heat treatment parameters are presented in Tab. 3 .

Table 3 Heat treatment parameters

\begin{tabular}{|c|c|c|c|c|}
\hline Batch & $\begin{array}{c}\text { Austenitization, } \\
{ }^{\circ} \mathrm{C} / \mathrm{min}\end{array}$ & $\begin{array}{c}\text { Deep cryogenic } \\
\text { treatment, }{ }^{\circ} \mathrm{C} / \mathrm{h}\end{array}$ & $\begin{array}{c}\text { Tempering, } \\
{ }^{\circ} \mathrm{C} / \mathrm{h}\end{array}$ & $\begin{array}{c}\text { Nitriding, } \\
{ }^{\circ} \mathrm{C} / \mathrm{h}\end{array}$ \\
\hline HT & $1130 / 6 \mathrm{~min}$ & - & $\begin{array}{c}520 / 520 / \\
490 / 2 \mathrm{~h}\end{array}$ & \\
\hline $\mathrm{HTN}$ & $1130 / 6 \mathrm{~min}$ & - & $\begin{array}{c}520 / 520 / \\
490 / 2 \mathrm{~h}\end{array}$ & $490 / 2.5 \mathrm{~h}$ \\
\hline DCT & $1130 / 6 \mathrm{~min}$ & $-196^{\circ} \mathrm{C} / 24 \mathrm{~h}$ & $520 / 2 \mathrm{~h}$ & \\
\hline DCTN & $1130 / 6 \mathrm{~min}$ & $-196^{\circ} \mathrm{C} / 24 \mathrm{~h}$ & $520 / 2 \mathrm{~h}$ & $490 / 2.5 \mathrm{~h}$ \\
\hline
\end{tabular}


After quenching, part of the test samples were soaked in liquid nitrogen at a controlled speed and left for $24 \mathrm{~h}$, followed by single tempering. Other samples were tempered three times. Part of the vacuum and deep cryogenic treated samples were plasma nitrided $\left(95 \% \mathrm{H}_{2}\right.$ and $\left.5 \% \mathrm{~N}_{2}\right)$. Nitriding in the duration of 2.5 hours was carried out at a temperature of $490{ }^{\circ} \mathrm{C}$ in a Metalplas Ionon BDAG GRUPPE BALCKEDÜRR AG apparatus. After heat treatment, thorough analysis of the microstructure and mechanical properties was performed on samples and the results were published in [19].

Wear resistance of specimens was determined by simulating two-body abrasive wear by alternating the sliding motion by using ball-on-flat contact with the $\mathrm{Al}_{2} \mathrm{O}_{3}$ ball as a counter-body with a hardness of $1200 \mathrm{HV}$ and a diameter of $\varnothing 10 \mathrm{~mm}$. Wear tests were performed under dry sliding conditions at an average sliding speed of $0.024 \mathrm{~m} / \mathrm{s}$ with a frequency of $5 \mathrm{~Hz}$ and amplitude of $2.4 \mathrm{~mm}$, maximum contact pressure of $1300 \mathrm{MPa}\left(F_{\mathrm{N}}=10 \mathrm{~N}\right)$ and total sliding distance of $30 \mathrm{~m}$, Fig. 2. Test results were evaluated in terms of the samples' wear rate $\left(\mathrm{mm}^{3} / \mathrm{Nm}\right)$ and average coefficient of friction. Testing was performed at room temperature (22 ${ }^{\circ} \mathrm{C}$ ) and relative humidity of $40 \%$.

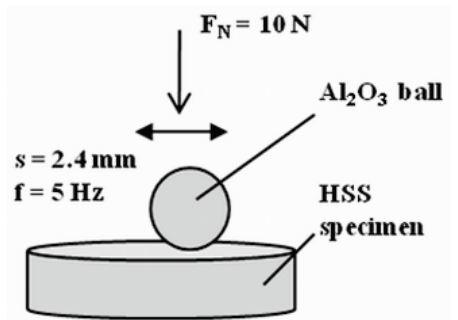

Figure 2 Schematic diagram of ball-on-flat wear test

The single point cutting tool machinability test was performed at the CNC turning machine SBL 500 TRENS with the parameters presented in Tab. 4. The material of the workpiece used in this test was annealed $\mathrm{X} 210 \mathrm{Cr} 12$ steel with a hardness of $240 \mathrm{HB}$.

Table 4 Turning parameters

\begin{tabular}{|c|c|c|c|}
\hline $\begin{array}{c}\text { Turning X210Cr12 steel with } \\
\text { HSS tools }\end{array}$ & $\begin{array}{c}\text { Cutting speed, } \\
\mathrm{m} / \mathrm{s}\end{array}$ & $\begin{array}{c}\text { Depth of cut, } \\
\mathrm{mm}\end{array}$ & $\begin{array}{c}\text { Feed, } \\
\mathrm{mm}\end{array}$ \\
\cline { 2 - 4 } & 30 & 0.5 & 0.1 \\
\hline
\end{tabular}

For every heat treatment batch, five HSS tool inserts were used with two cutting edges. Tool wear was measured after every two minutes of turning by measuring the flank wear, $V B$, by using the Tescan Vega TS5136LS scanning electron microscope. The criterion for the end of tool life was the catastrophic failure of five 2-minute cycles of turning, i.e. a total of 10 minutes. $V B$ was the width of the flank wear track at the edge of the flank, Fig. 3. The results represent the mean value of ten measurements.

\section{RESULTS AND DISCUSSION}

The results of the abrasion wear testing show that DCT and nitriding resulted in lower wear rates of the high-speed steel specimens tested against alumina ball counter-body. The results are presented in Figure 4. Deep cryogenic treatment resulted in a $23.6 \%$ reduction of the wear rate. Nitriding resulted in an approximately $18.4 \%$ reduction of the wear rate and in combination with DCT $25.6 \%$ respectively.

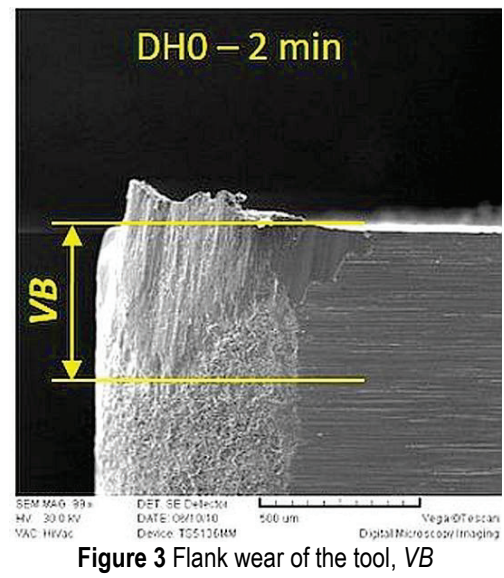

The results show that nitriding after deep cryogenic treatment did not significantly influence the reduction in wear rate as it influenced the wear rate after heat treatment. Regarding the coefficient of friction, DCT samples had a bit higher coefficient of friction, approximately $4 \%$ higher than classically heat-treated samples. Through nitrogen diffusion layer formation $[19,20]$, plasma nitriding reduced friction coefficient of the analysed steel in classic heat-treated samples (HTN) and DCTN samples for $8 \%$ and $11 \%$, respectively.

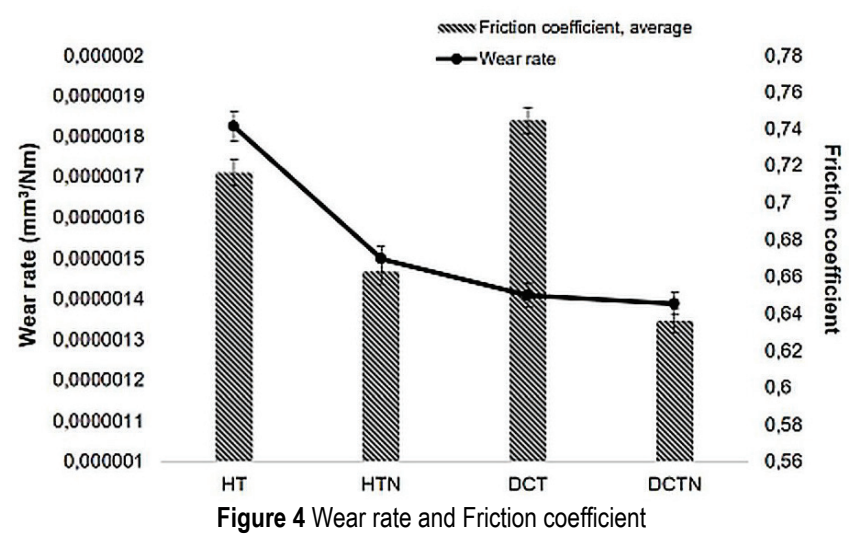

Fig. 5 presents the values of the average flank wear of the cutting tool inserts measured every two minutes of turning. The results show that after two minutes, heat treated (HT) inserts had the highest value of average flank wear, but after four minutes of turning, the cryogenically treated and nitrided (DCTN) tool inserts had higher flank wear values than the heat treated (HT) ones. The heat-treated inserts (HT) and cryogenically treated and nitrided (DCTN) inserts had total tool failure after eight minutes of turning with flank wear values above $1.2 \mathrm{~mm}$. The DCT inserts and heat-treated and nitrided (HTN) inserts exhibited similar wear behaviour with slightly lower flank wear values for the heat-treated and nitrided (HTN) tool inserts. When compared with the 
laboratory wear test results, it can be observed that the DCT samples had a lower wear rate than the HTN samples and that the DCTN samples exhibited the lowest wear rate of all samples, and in the machinability test, the DCTN tool inserts had the poorest wear behaviour. Similar results were reported in [5], where it was concluded by the authors that plasma nitriding enhances the tribological properties of powder metallurgy HSS, but if combined with the DCT, it might reduce the advantageous effect of the deep-cryogenic treatment and the reasons for that are not clear at present.

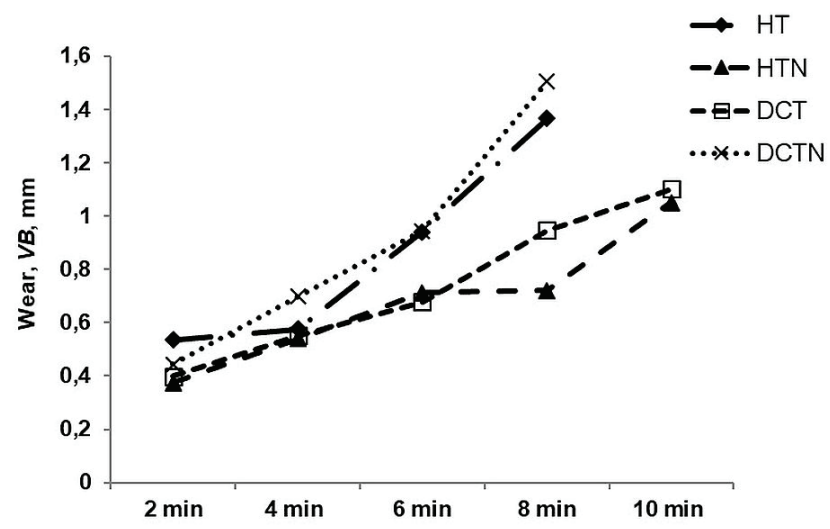

Figure 5 Average flank wear of differently heat treated HSS cutting tool inserts

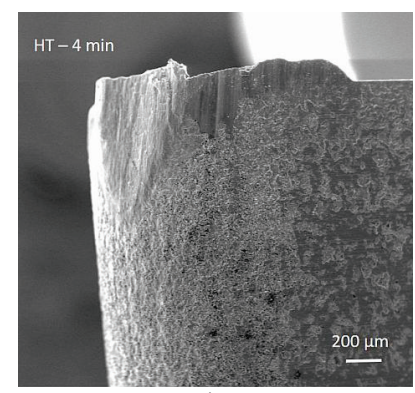

a)

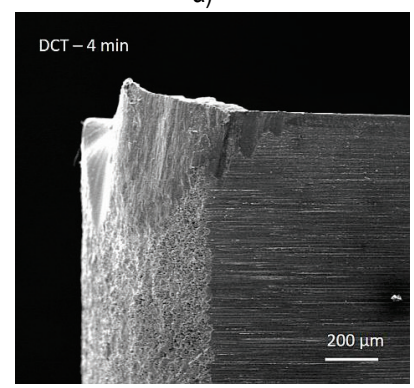

c)

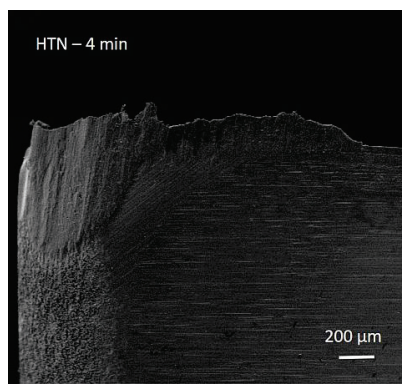

b)

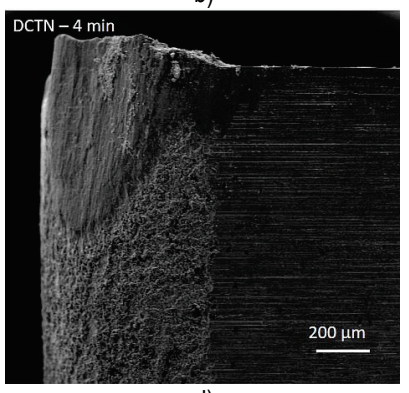

d)
Figure 6 Flank wear of differently HSS heat-treated inserts

a) Classically heat treated HSS; b) Classically heat treated and nitrided HSS

c) Deep cryogenic treated HSS; d) Deep cryogenic treated and nitrided HSS

Although the laboratory tests gave the results on wear behaviour of the cryogenically treated and nitrided HSS, they cannot predict the behaviour of HSS tools under the realistic wear condition, e.g. cutting processes which involve high temperatures at the tool - chip contact, high stress on the tool surfaces and intense interaction between the tool and the workpiece. It is clear that at the cutting speed of $30 \mathrm{~m} / \mathrm{min}$ diffusion and oxidation, wear mechanisms were also pronounced at a higher rate and they contributed to the intensity of the cutting tool insert flank face wear.

Fig. 6 shows wear of the cutting inserts flank face and the formation of a build-up edge of the flank face in all four cutting inserts can be observed. The build-up edge is formed as a result of indirect adhesion wear [21].

Adhesion wear is one of the tool wear mechanisms that can be present in a wider range of cutting temperatures. It can be produced by two different ways. Direct adhesion wear is caused by the integration of tool particles to the chips, and indirect or secondary adhesion wear is caused by an integration of a fragment of the workpiece material to the tool. This affects tool wear in the way that tool geometry is altered by material integration and when these fragments are removed, they can extract tool particles causing tool wear [21]. As observed in Fig. 6 d, the highest build-up edge after four minutes of turning is present at the DCTN insert even though DCTN samples had the lowest coefficient of friction in the laboratory wear test. This is also in accordance with [5], where it was concluded after the laboratory wear tests performed on samples, that plasma nitriding in combination with DCT might eliminate the advantageous effect of DCT, leading to reduced galling resistance. Galling resistance reduction also had a large influence on the results in the machinability test performed within this research since galling is a very intense form of adhesion wear. Adhesion wear leads to the formation of a build-up edge of the tool flank face intensifying the wear of the cutting tool.

\section{CONCLUSION}

Properly optimized and conducted heat treatment can notably affect the properties of high-speed steels. The heat treatment parameters of HSS are chosen depending on the required specific properties of the particular tool. With different combinations of deep cryogenic treatment parameters and nitriding, it is possible to affect the mechanical properties (hardness and fracture toughness) of certain components, but it can also increase wear resistance regardless of the changes in hardness values.

In this paper, the influence of nitriding in combination with deep cryogenic treatment on the abrasion wear resistance and coefficient of the friction of high-speed steel produced with powder metallurgy was investigated. In addition to that, its behaviour under the realistic wear condition, i.e. the cutting process, was observed, by performing the single point cutting tool machinability test and measuring the flank wear every two minutes. The results showed that deep cryogenic treatment resulted in a $23.6 \%$ reduction of the wear rate and nitriding in an approximately $18.4 \%$ reduction of the wear rate, in combination with the deep cryogenic treatment of $25.6 \%$ respectively. The results show that nitriding after deep cryogenic treatment did not influence significantly the reduction in the wear rate as it influenced the wear rate when conducted after the heat treatment. Regarding the coefficient of friction, deep cryogenic treatment samples had an approximately $4 \%$ higher coefficient of friction than the classically heat-treated samples. Plasma nitriding reduced the friction coefficient of 
the analysed steel in the classically heat-treated samples and deep cryogenic treated samples for $8 \%$ and $11 \%$, respectively. Regarding the behaviour of HSS in the machinability test, the heat-treated (HT) inserts and deep cryogenic treated and nitrided (DCTN) inserts exhibited a total tool failure after eight minutes of turning with flank wear values above $1.2 \mathrm{~mm}$.

DCT inserts and heat-treated and nitrided (HTN) inserts exhibited similar wear behaviour through the machinability test with slightly lower flank wear values for the heat-treated and nitrided (HTN) tool inserts. When compared to the laboratory wear test results, it can be observed that the DCT samples had a lower wear rate than the HTN samples and that the DCTN samples exhibited the lowest wear rate of all samples and in the machinability test, the DCTN tool inserts had the poorest wear behaviour.

Based on the results of the machinability test, it can be concluded that when high-speed steel is subjected to conditions in the real cutting process, classical heat treatment and nitriding have the same effect as DCT and in combination with DCT, plasma nitriding eliminates the advantageous effect of the deep-cryogenic treatment.

\section{REFERENCES}

[1] Holmberg, K. \& Matthews, A. (1994). Coatings Tribology, Elsevier Science B. V., Amsterdam.

[2] Soković, M., Barišić, B., \& Sladić, S. (2009). Model of quality management of hard coatings on ceramic cutting tools. Journal of Materials Processing Technology, 209, 4207-4216. https://doi.org/10.1016/j.jmatprotec.2008.11.026

[3] Šlić, S. (2011). Influence of the microstructure on the tribological properties of cutting tools, doctoral thesis, Zagreb, UniZg, FAMENA. (in Croatian)

[4] Šolić, S., Schauperl, Z., Godec, M. \& Tropša, V. (2017). Microstructural changes in heat treatment of PM high-speed steels. Tehnički glasnik, 11(4), 166-170.

[5] Podgornik, B., Majdic, F., Leskovšek, V., \& Vizintin, J. (2012). Improving tribological properties of tool steels through combination of deep-cryogenic treatment and plasma nitriding. Wear, 288, 88-93. https://doi.org/10.1016/j.wear.2011.04.001

[6] Meng, F., Tagashira, K., Azuma, R., \& Sohma, H. (1994). Role of eta-carbide precipitations in the wear resistance improvements of $\mathrm{Fe}-12 \mathrm{Cr}-\mathrm{Mo}-\mathrm{V}-1.4 \mathrm{C}$ tool steel by cryogenic treatment. ISIJ International, 34, 205-210. https://doi.org/10.2355/isijinternational.34.205

[7] Meng, F., Tagashira, K., Azuma, R., \& Sohma, H. (1994). Role of eta-carbide precipitation's in the wear resistance improvements Fe-12Cr-Mo-V-1,4C tool steel by cryogenic treatment. ISIJ International, 34(2), 205-210. https://doi.org/10.2355/isijinternational.34.205

[8] Leskovšek, V., Kalin, M., \& Vižintin, J. (2006). Influence of deep-cryogenic treatment on wear resistance of vacuum heattreated HSS. Vacuum, 80, 507-518. https://doi.org/10.1016/j.vacuum.2005.08.023

[9] Leskovšek, V. \& Ule, B. (1998). Improved vacuum heattreatment for fine-blanking tools from high speed steel M2. Journal of Material Processing Technology, 82, 89-94. https://doi.org/10.1016/S0924-0136(98)00023-5

[10] Molinari, A., Pellizzari, M., Gialanella, S., Straffelini, G., \& Stiasny, K. H. (2001). Effect of deep cryogenic treatment on the properties of tool steel. J. Mater. Process. Technol., 118, 350-355. https://doi.org/10.1016/S0924-0136(01)00973-6

[11] Mohan Lal, D., Renganarayanan, S., Kalanidhi, A. (2001). Cryogenic treatment to augment wear resistance of tool and die steels. Cryogenics, 41, 149-155. https://doi.org/10.1016/S0011-2275(01)00065-0

[12] Baldissera, P. \& Delprete, C. (2008). Deep Cryogenic Treatment: A Bibliographic Review. The Open Mechanical Engineering Journal, 2, 1-11. https://doi.org/10.2174/1874155X00802010001

[13] Oppenkowski, A., Weber, S., \& Theisen, W. (2010). Evaluation of factors influencing deep cryogenic treatment that affect the properties of tool steels. J. Mater. Process. Technol., 210, 1949-1955. https://doi.org/10.1016/j.jmatprotec.2010.07.007

[14] Podgornik, B., Paulin, I., Zajec, B., Jacobson, S., \& Leskovšek, V. (2016). Deep cryogenic treatment of tool steels. Journal of Materials Processing Technology, 229, 398-406. https://doi.org/10.1016/j.jmatprotec.2015.09.045

[15] Silva, F. J., Franco, S. D., Machado, A. R., Ezugwu, E. O., Souza, A. M. J. (2006). Performance of cryogenically treated HSS tools. Wear, 261, 674-685. https://doi.org/10.1016/j.wear.2006.01.017

[16] Firouzdor, V., Nejati, E., \& Khomamizadeh, F. (2008). Effect of deep cryogenic treatment on wear resistance and tool life of M2 HSS drill. Journal of Materials Processing Technology, 206, 467-472. https://doi.org/10.1016/j.jmatprotec.2007.12.072

[17] Yan, X. G. \& Li, D. Y. (2013). Effects of the sub-zero treatment condition on microstructure, mechanical behavior and wear resistance of W9Mo3Cr4V high speed steel. Wear, 302(1-2), 854-862. https://doi.org/10.1016/j.wear.2012.12.037

[18] www.iscar.com

[19] Šolić, S., Cajner, F., \& Leskovšek, V. (2012). Effect of Deep Cryogenic Treatment on Mechanical and Tribological Properties of PM S390 MC High-Speed Steel. Materials Testing, 54(10), 688-693. https://doi.org/10.3139/120.110380

[20] Kato, H. \& Eyre, T. S. (1994). Sliding wear characteristics of nitrided steels. Surf. Eng., 10, 65-74. https://doi.org/10.1179/sur.1994.10.1.65

[21] Gómez-Parra, A., Álvarez-Alcón, M., Salguero, J., Batista, M., \& Marcos, M. (2013). Analysis of the evolution of the BuiltUp Edge and Built-Up Layer formation mechanisms in the dry turning of aeronautical aluminium alloys. Wear, 302(1-2), 1209-1218. https://doi.org/10.1016/j.wear.2012.12.001

\section{Authors' contacts: \\ Dr. sc. Sanja ŠoLĆ, Assistant Professor \\ University North, Department of Mechanical Engineering \\ J. Križanića 31b, 42000 Varaždin, Croatia \\ E-mail: sanja.solic@unin.hr}

Dr. sc. Zdravko SCHAUPERL, Full Professor

University of Zagreb, Faculty for Mechanical Engineering and Naval Architecture,

Ivana Lučića 5, 10000 Zagreb, Croatia

E-mail: zdravko.schauperl@fsb.hr

Dr. sc. Vlado TROPŠA, Associate Professor

University North, Department for Mechanical Engineering

J. Križanića 31b, 42000 Varaždin, Croatia

E-mail: vlado.tropsa@unin.hr 